\title{
Lipid Alterations in Lipid Rafts from Alzheimer's Disease Human Brain Cortex
}

\author{
Virginia Martín $^{\mathrm{a}, \mathrm{b}}$, Noemí Fabelo ${ }^{\mathrm{a}, \mathrm{b}}$, Gabriel Santpere ${ }^{\mathrm{c}}$, Berta Puig ${ }^{\mathrm{c}}$, Raquel Marín ${ }^{\mathrm{a}, \mathrm{d}}$, Isidre Ferrer ${ }^{\mathrm{c}}$ and \\ Mario Díaz ${ }^{\mathrm{a}, \mathrm{b}, *}$ \\ anstituto de Tecnologías Biomédicas, Universidad de La Laguna, Tenerife, Spain \\ ${ }^{\mathrm{b}}$ Departamento de Biología Animal, Universidad de La Laguna, Tenerife, Spain \\ ${ }^{\mathrm{c}}$ Institut Neuropatologia, Servei Anatomia Patologica, Hospital Universitari de Bellvitge, Universitat de \\ Barcelona, Hospitalet de Llobregat, CIBERNED, Spain \\ ${ }^{\mathrm{d}}$ Departamento de Fisiología, Universidad de La Laguna, Tenerife, Spain
}

Accepted 31 July 2009

\begin{abstract}
Lipid rafts are membrane microdomains intimately associated with cell signaling. These biochemical microstructures are characterized by their high contents of sphingolipids, cholesterol and saturated fatty acids and a reduced content of polyunsaturated fatty acids (PUFA). Here, we have purified lipid rafts of human frontal brain cortex from normal and Alzheimer's disease (AD) and characterized their biochemical lipid composition. The results revealed that lipid rafts from AD brains exhibit aberrant lipid profiles compared to healthy brains. In particular, lipid rafts from AD brains displayed abnormally low levels of n-3 long chain polyunsaturated fatty acids (LCPUFA, mainly 22:6n-3, docosahexaenoic acid) and monoenes (mainly 18:1n-9, oleic acid), as well as reduced unsaturation and peroxidability indexes. Also, multiple relationships between phospholipids and fatty acids were altered in AD lipid rafts. Importantly, no changes were observed in the mole percentage of lipid classes and fatty acids in rafts from normal brains throughout the lifespan (24-85 years). These indications point to the existence of homeostatic mechanisms preserving lipid raft status in normal frontal cortex. The disruption of such mechanisms in AD brains leads to a considerable increase in lipid raft order and viscosity, which may explain the alterations in lipid raft signaling observed in AD.
\end{abstract}

Keywords: Alzheimer's disease, docosahexaenoic acid, human brain cortex, lipid rafts, membrane phospholipids, polyunsaturated fatty acids

\section{INTRODUCTION}

Lipid rafts have been defined as cholesterol and sphingolipid enriched membrane microdomains resistant to solubilization by non-ionic detergents at low temperatures. They may serve as platforms for intracellular cell signaling by promoting protein-protein and protein-lipid interactions $[1,2]$

Alterations in the molecular composition and cell distribution of lipid rafts might have implications in

* Corresponding author: Dr. Mario Díaz, U.D.I. Fisiología Animal, Departamento de Biología Animal, Universidad de La Laguna, 38206 Tenerife, Spain. Tel.: +34 922318343; Fax: +34 922318342; E-mail: madiaz@ull.es. pathological events. There is increasing evidence that lipid rafts may be targets of neurodegenerative diseases such as Alzheimer's disease (AD) $[3,4]$. AD, the most common form of dementia, is a progressive degenerative disease of the brain characterized clinically by progressive loss of memory and cognitive function. Neuropathologically, AD is characterized by senile plaques and neurofibrillary tangles [5]. The main component of senile plaques is amyloid, which consist mainly of aggregated variants of amyloid $\beta$-protein $(\mathrm{A} \beta)$, a family of 39-42 residue peptides formed by two sequential enzyme cleavage of the amyloid- $\beta$ protein precursor $(\mathrm{A} \beta \mathrm{PP}) . \mathrm{A} \beta \mathrm{PP}$ is initially cleaved by $\beta$-secretase followed by the subsequent intramembrane proteolyses of the membrane bound C-terminal fragment cat- 
alyzed by $\gamma$-secretase. Lipid rafts may play an important role in proteolytic processing and regulation of $\mathrm{A} \beta \mathrm{PP}$ cleavage, and recent reports have shown that $\mathrm{A} \beta \mathrm{PP}$ itself is expressed in lipid rafts [6-8]. In addition, AD-related components, such as the $\mathrm{A} \beta \mathrm{PP} \mathrm{N}$-terminal fragment [9], the $\mathrm{A} \beta$-bearing $\mathrm{C}$-terminal fragment produced by $\beta$-secretase [10], $\alpha$-secretase [11,12], BACE1 $(\beta$-secretase $)[13,14]$, and PSEN1 $(\gamma$-secretase $)[10$, 15-17], as well as apolipoprotein E (ApoE) and tau have been identified in lipid rafts of cultured cells and mammalian brains.

Long chain polyunsaturated fatty acids (LCPUFA), mainly docosahexaenoic acid (DHA; 22:6n-3), are particularly enriched in cell membrane phospholipids, especially in neural tissues $[18,19]$. Several studies have shown that these fatty acids are important for the proper development and physiology of neuronal cells and their deficiency has been associated with AD [20-25]. Also, LCPUFAs such as DHA have the capacity to influence plasma membrane organization and activity by modulating the lipid composition and functionality of lipid raft domains [26-28,30,31]. These observations suggest that lipid rafts are likely molecular targets through which long chain n-3 PUFA modulate diverse biochemical activities, and reduce the incidence and severity of human diseases.

Considering the importance of lipid raft signaling in the pathogenesis of AD and that these specific membrane domains are putative targets for pharmacological approaches in the prevention of the disease, the aim of this study was to examine the lipid classes and fatty acid composition of lipid rafts from frontal cortex of human brains, one of the main areas affected in $\mathrm{AD}$, to explore possible lipid profile alterations that could correlate with this neuropathology. This is the first detailed biochemical study on lipid raft fatty acid composition in human brains.

\section{MATERIALS AND METHODS}

\section{Human brain tissue}

Brain tissues were obtained from the Institute of Neuropathology Brain Bank (Hospital Universitari de Bellvitge, Spain) following the guidelines of the local ethics committee. 10 patients had suffered from severe (Global deterioration scale) dementia of Alzheimer type. 20 cases were neurologically normal. The postmortem delays were between 3 and $18 \mathrm{~h}$. Frontal cortex tissue (cortex area VIII) were used for the isolation of lipid rafts. Cases were divided into three categories: AD group (patients with Alzheimer's disease and average age $81.2 \pm 2.48$ years), $\mathrm{C}>60$ group (an agematched control obtained from subjects showing no lesions and average age $74.0 \pm 2.16$ years old), and C $<60$ group (samples from subjects showing no lesions and average age $42.4 \pm 2.41$ years). A summary of the main clinical and neuropathological aspects of all cases examined is shown in Table 1.

Cases with and without clinical neurological disease were processed in the same way following the same sampling and staining protocols. At autopsy, half of each brain was fixed in $10 \%$ buffered formalin, while the other half was cut in coronal sections $1 \mathrm{~cm}$ thick, frozen on dry ice, and stored at $-80^{\circ} \mathrm{C}$ until use. In addition, samples of the frontal cortex were fixed in $4 \%$ paraformaldehyde in phosphate buffer for $24 \mathrm{~h}$, cryoprotected in $30 \%$ sucrose and frozen at $-80^{\circ} \mathrm{C}$. The neuropathological study was carried out on de-waxed $4 \mu \mathrm{m}$-thick paraffin sections of the frontal cortex (area 8). The sections were stained with haematoxylin and eosin, Klüver Barrera, and, for immunohistochemistry to glial fibrillary acidic protein, CD68 and Licopersicum esculentum lectin for microglia, $\mathrm{A} \beta$-amyloid, pan-tau, AT8 tau, phosphorylation-specific tau Thr181, Ser202, Ser214, Ser262, Ser396 and Ser422, and $\alpha$ Bcrystallin, $\alpha$-synuclein and ubiquitin. Following neuropathological examination, 10 cases were categorized as AD stages V/VIC of Braak et al. [32], modified for paraffin sections [33]. The main clinical and neuropathological findings in the present series are summarized in Table 1.

\section{Isolation of lipid rafts, non-raft fractions and microsomes}

Samples of frontal cortex grey matter were carefully dissected out to avoid contamination with white matter. Lipid raft fractions were isolated following Mukherjee et al. [34] with slight modifications. Briefly, $0.1 \mathrm{~g}$ of frontal cortex was homogenized in 8 volumes of buffer A $\left(50 \mathrm{mM}\right.$ Tris- $\mathrm{HCl}, \mathrm{pH} 8.0,10 \mathrm{mM} \mathrm{MgCl}_{2}, 20 \mathrm{mM}$ $\mathrm{NaF}, 1 \mathrm{mM} \mathrm{Na} \mathrm{VO}_{4}, 5 \mathrm{mM} \beta$-mercaptoethanol, $1 \mathrm{mM}$ PMSF) and a cocktail of proteases inhibitors (Roche Diagnostics, Barcelona, Spain) containing 1\% Triton $\mathrm{X}-100$ and 5\% glycerol in a glass homogenizer grinder. All steps in the protocol were performed on ice or in a cold room at $4{ }^{\circ} \mathrm{C}$. Tissue was then centrifuged at 500 $\mathrm{x} g$ for $5 \mathrm{~min}$ and the supernatant was collected and mixed in an orbital rotor for $1 \mathrm{~h}$ at $4{ }^{\circ} \mathrm{C}$. About $800 \mu \mathrm{l}$ of sample was mixed with an equal volume of $80 \%$ 
Table 1

Summary of cases

\begin{tabular}{|c|c|c|c|c|c|}
\hline Case & $\begin{array}{c}\text { Age } \\
\text { (years) }\end{array}$ & Gender & $\begin{array}{c}\text { Postmortem } \\
\text { delay }\end{array}$ & $\begin{array}{c}\text { Neuropathological } \\
\text { diagnosis }\end{array}$ & Braak stage \\
\hline \multicolumn{6}{|c|}{ Control samples with age $<60$ (group $\mathrm{C}<60)$} \\
\hline 1 & 38 & M & $18 \mathrm{~h}$ & NL & 0 \\
\hline 2 & 49 & M & $7 \mathrm{~h} 35 \mathrm{~min}$ & NL & 0 \\
\hline 3 & 40 & M & $9 \mathrm{~h} 15 \mathrm{~min}$ & NL & 0 \\
\hline 4 & 39 & M & $3 \mathrm{~h} 30 \mathrm{~min}$ & NL & 0 \\
\hline 5 & 47 & M & $4 \mathrm{~h} 55 \mathrm{~min}$ & NL & 0 \\
\hline 6 & 45 & $\mathrm{~F}$ & $14 \mathrm{~h} 40 \mathrm{~min}$ & NL & 0 \\
\hline 7 & 24 & $\mathrm{~F}$ & $6 \mathrm{~h}$ & NL & 0 \\
\hline 8 & 46 & $\mathrm{~F}$ & $14 \mathrm{~h} 5 \mathrm{~min}$ & NL & 0 \\
\hline 9 & 49 & $\mathrm{~F}$ & $7 \mathrm{~h}$ & NL & 0 \\
\hline 10 & 47 & $\mathrm{~F}$ & $9 \mathrm{~h} 35 \mathrm{~min}$ & NL & 0 \\
\hline \multicolumn{6}{|c|}{ Control samples with age $>60$ (group $C>60)$} \\
\hline 11 & 79 & M & $7 \mathrm{~h}$ & NL & 0 \\
\hline 12 & 85 & M & $5 \mathrm{~h} 45 \mathrm{~min}$ & NL & 0 \\
\hline 13 & 70 & M & $13 \mathrm{~h}$ & NL & 0 \\
\hline 14 & 78 & M & $2 \mathrm{~h} 15 \mathrm{~min}$ & NL & 0 \\
\hline 15 & 71 & M & $12 \mathrm{~h}$ & NL & 0 \\
\hline 16 & 82 & $\mathrm{~F}$ & $11 \mathrm{~h}$ & NL & 0 \\
\hline 17 & 75 & $\mathrm{~F}$ & $3 h$ & NL & 0 \\
\hline 18 & 66 & $\mathrm{~F}$ & $8 \mathrm{~h}$ & NL & 0 \\
\hline 19 & 69 & $\mathrm{~F}$ & $2 \mathrm{~h} 30 \mathrm{~min}$ & NL & 0 \\
\hline 20 & 65 & $\mathrm{~F}$ & $4 \mathrm{~h}$ & NL & 0 \\
\hline \multicolumn{6}{|c|}{ AD samples (group AD) } \\
\hline 21 & 69 & M & $6 \mathrm{~h}$ & $\mathrm{AD}$ & VC \\
\hline 22 & 93 & M & $7 \mathrm{~h} 20 \mathrm{~min}$ & $\mathrm{AD}$ & $\mathrm{VC}$ \\
\hline 23 & 79 & M & $7 \mathrm{~h} 25 \mathrm{~min}$ & $\mathrm{AD}+\mathrm{AmA}$ & $\mathrm{VC}$ \\
\hline 24 & 73 & M & $2 \mathrm{~h} 30 \mathrm{~min}$ & $\mathrm{AD}$ & VIC \\
\hline 25 & 86 & M & $4 \mathrm{~h} 15 \mathrm{~min}$ & $\mathrm{AD}+\mathrm{AmA}$ & $\mathrm{VC}$ \\
\hline 26 & 86 & $\mathrm{~F}$ & $10 \mathrm{~h}$ & $\mathrm{AD}$ & VC \\
\hline 27 & 83 & $\mathrm{~F}$ & $5 \mathrm{~h}$ & $\mathrm{AD}$ & $\mathrm{VC}$ \\
\hline 28 & 82 & $\mathrm{~F}$ & $1 \mathrm{~h} 45 \mathrm{~min}$ & $\mathrm{AD}+\mathrm{AmA}$ & $\mathrm{VC}$ \\
\hline 29 & 72 & $\mathrm{~F}$ & $9 \mathrm{~h} 30 \mathrm{~min}$ & $\mathrm{AD}$ & $\mathrm{VC}$ \\
\hline 30 & 89 & $\mathrm{~F}$ & $4 \mathrm{~h}$ & $\mathrm{AD}$ & $\mathrm{VC}$ \\
\hline
\end{tabular}

M: male; F: female; NL: no lesions; AD: Alzheimer disease; AmA: amyloid angiopathy. V/VI: refers to Braak and Braak stages of AD-related changes; V/VI: neurofibrillary tangle distribution in the neocortex; $\mathrm{C}$ : large numbers of senile plaques in the neocortex.

sucrose in buffer A and overlayed with $7.5 \mathrm{ml}$ of a $35 \%$ sucrose solution and $2.7 \mathrm{ml}$ of a $15 \%$ sucrose solution in buffer $\mathrm{A}$, in $10 \mathrm{ml}$ ultracentrifuge tubes (Ultraclear, Beckman). Sucrose gradients were centrifuged at $150,000 \times \mathrm{g}$ for $18 \mathrm{~h}$ at $4^{\circ} \mathrm{C}$ in a Beckman SW41Ti rotor. Fractions of $2 \mathrm{ml}$ were collected from the top to the bottom and the final pellet, corresponding to the precipitated detergent soluble fractions, i.e., non-rafts fractions, were collected and resuspended in $200 \mu \mathrm{l}$ of buffer A and frozen until analyses.

Microsomal fractions of grey matter frontal cortex samples were obtained by homogenization in RSB buffer (10 mM Tris-HCl, pH 8.0, $20 \mathrm{mM} \mathrm{NaCl}, 25 \mathrm{mM}$ EDTA and complete proteases inhibitor cocktail), using a Teflon-glass homogenizer grinder. The whole procedure was carried out at $4{ }^{\circ} \mathrm{C}$. The tissue homogenate was first centrifuged at $900 \times \mathrm{g}$ for $15 \mathrm{~min}$ and the su- pernatant was centrifuged at $10,000 \times \mathrm{g}$ for $15 \mathrm{~min}$ to sediment the mitochondrial fraction. A second supernatant was collected, and centrifuged at 100,000 x $g$ at $4{ }^{\circ} \mathrm{C}$ in a Beckman SW55Ti rotor following standard protocols to sediment microsomal fractions.

For the protein characterization of lipid rafts, nonrafts and microsomes, samples were resuspended in SDS loading buffer $(625 \mathrm{mM}$ Tris- $\mathrm{HCl} \mathrm{pH} 6.8 ; 1 \%$ SDS, $10 \%$ glycerol, $5 \% \quad \beta$-mercaptoethanol; $0.01 \%$ bromophenol blue), boiled at $95^{\circ} \mathrm{C}$ for $5 \mathrm{~min}$, and proceeded for SDS-PAGE and Western blotting. Samples were probed for the mouse anti-flotillin-1 antibody (610820, BD Biosciences,) and the monoclonal anti-PrP antibody (S2022, Clone 3F4, Dako), both at 1:1000, the rabbit polyclonal anti-caveolin-1 (sc-894, Santa Cruz Biotech., diluted 1:200), and the rabbit polyclonal anti-A $\beta$ PP (ab17467, Abcam, diluted 1:500) to 
identify raft-enriched fractions. The mouse monoclonal antibodies against the non-raft membrane and microsomal proteins $\alpha_{1}$ subunit of the $\mathrm{Na}^{+} / \mathrm{K}^{+}$ATPase (05-369, Upstate) and clathrin (C1860, Sigma Aldrich), both diluted at 1:1000, were used as controls of lipid rafts purity. The mouse anti-SOD1 antibody, raised against a prokaryotic recombinant fusion protein corresponding to the $\mathrm{N}$-terminal domains I to $\mathrm{V}$ of the $\mathrm{Cu} / \mathrm{Zn}$ superoxide dismutase (SOD-1) molecule (NCL-SOD1, Novocastra Laboratories, diluted 1:1600), was used as a cytosolic marker.

\section{Lipid analyses}

Total lipids from lipid rafts and non-raft fractions were extracted with chloroform/methanol $(2: 1 \mathrm{v} / \mathrm{v})$ containing $0.01 \%$ of butylated hydroxytoluene (BHT) as antioxidant [35]. Lipid classes were separated from a fraction of total lipid by one-dimensional double development high performance thin layer chromatography (HPTLC), and were quantified by densitometry [36]. Equal amounts of total lipids (30 $\mu \mathrm{g})$ were used in all analyses.

Lipids from lipid rafts and non-raft fractions were subjected to acid-catalyzed transmethylation with $1 \%$ sulfuric acid $(\mathrm{v} / \mathrm{v})$ in methanol. The resultant fatty acid methyl esters (FAME) were purified by thin layer chromatography (TLC) [35]. FAME were separated and quantified by using a Shimadzu GC-14A gas chromatograph equipped with a flame ionization detector $\left(250^{\circ} \mathrm{C}\right)$ and a fused silica capillary column Supelcowax ${ }^{\mathrm{TM}} 10(30 \mathrm{~m} \times 0.32 \mathrm{~mm}$ I.D. $)$. Individual FAME were identified by referring to authentic standards.

Unsaturation index was calculated as $\sum \mathrm{m}_{i} \mathrm{n}_{i}$, where $\mathrm{m}_{i}$ is the mole percentage and $\mathrm{n}_{i}$ is the number of carbon-carbon double bonds of the fatty acid. The peroxidability index was calculated following Cosgrove et al. [37] as $\sum$ monoenoic $* 0,025+\sum$ dienoic $+\sum$ trienoic $* 2+\sum$ tetraenoic $* 3+\sum$ pentaenoic $* 6+\sum$ hexaenoic $* 8$.

\section{Statistical analyses}

Comparison between groups was assessed either by one-way ANOVA followed by Tukey's post-hoc test or Kruskal-Wallis followed by Games-Howell post-hoc test depending on the homocedasticity and normality of experimental data. Data from univariate and bivariate statistics are expressed as mean \pm SEM. Statistical significance is indicated in the figures and tables from $p<0.05$. Pearson correlation coefficients were used to express bivariate relationships between independent variables (lipid parameters and age on one side, and fatty acids and lipid classes on the other). Multivariate statistics were performed using multivariate analyses of variance (MANOVA) followed by discriminant function analysis. Predictive variables were chosen according to the number of cases in each group to fulfill the assumptions of discriminant analysis [38]. Data were arcsin transformed (percent lipid content) or log-transformed (age) in order to attain the assumption of normality. Individual canonical scores of each case and centroids of each group were calculated using the SPSS statistical package (version 15), and then plotted in order to predict which group a particular individual case belonged (Fig. 4).

\section{RESULTS}

\section{Characterization of lipid rafts}

Purity of isolated lipid rafts was confirmed by demonstrating the enrichment of flotillin-1, the prototipical raft marker protein in the corresponding fraction (Fig. 1A). Similarly, the prion-related protein PrP, a protein known to be localized in neuronal lipid rafts, appeared concentrated in fraction 1 while the $\mathrm{Cu} / \mathrm{Zn}$ superoxide dismutase 1 (SOD-1), a cytosolic marker, was completely excluded from this particular fraction.

To confirm whether lipid rafts (fraction 1) were free of non-raft material, we performed additional immunoblotting experiments to compare the presence of raft and non-raft membrane associated proteins between microsomes (M), non-raft fraction (NR), and lipid raft fraction 1 (LR) (Fig. 1B). Results demonstrated the presence of flotillin-1 and caveolin-1, another hallmark of lipid rafts, in fraction 1 and microsomes that were not present in non-raft fractions. A similar pattern was obtained for $\mathrm{A} \beta \mathrm{PP}$, known to be mainly localized in neuronal lipid rafts. In contrast, the integral membrane $\mathrm{Na}^{+} / \mathrm{K}^{+}$ATPase $\alpha_{1}$ subunit, and the membrane vesicle coated protein clathrin, which are non-raft and microsome associated, were not detected in lipid rafts.

In order to demonstrate the purity of lipid rafts, we performed additional analyses on the lipid profile of lipid rafts and non-raft fractions. The results summarized in Fig. 1C demonstrated that isolated lipid raft fraction 1 exhibit significantly higher amounts of sphingomyelin ( $\mathrm{SM}, \sim 11 \%$ ), cholesterol $(\mathrm{CHO}, \sim 35 \%$ ), and saturated fatty acids $(\sim 50 \%)$ compared to non- 
A)
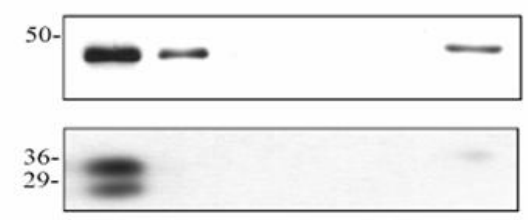

Flotillin

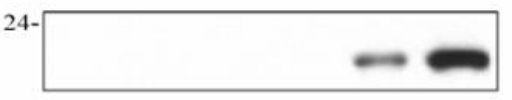

PrP

SOD-1
B)
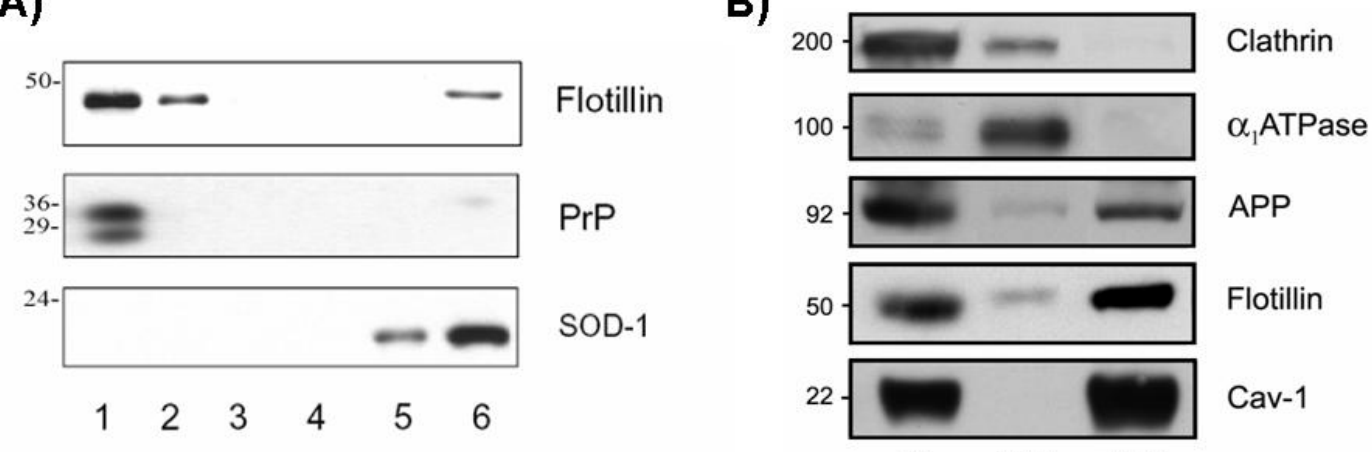

C)
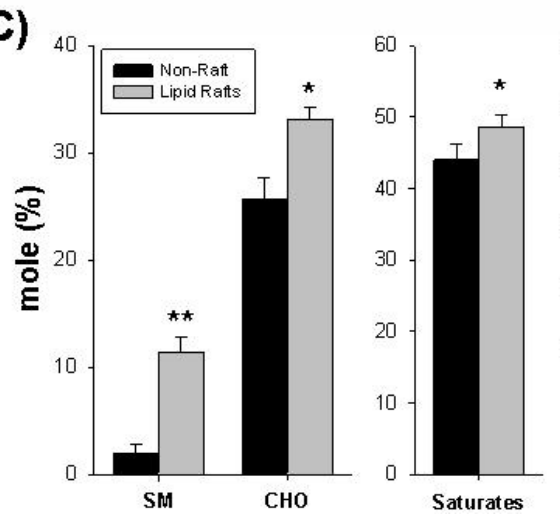

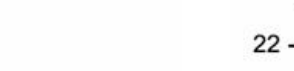

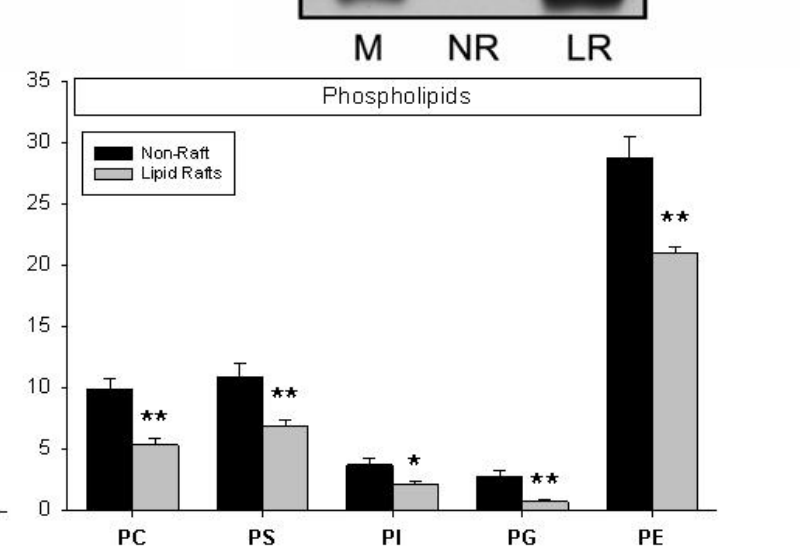

Fig. 1. (A) Western blot characterization of frontal cortex lipid rafts. Illustrated corresponds to a subject from group C $>60$. Lipid raft resident proteins as flotillin-1 and PrP are found mainly in fractions 1 and 2 whereas cytosolic protein SOD-1 is found in soluble fractions 5 and 6 . (B) Comparison of protein markers present in microsomal fraction (M), non-raft fractions (NR) and lipid rafts (LR) extracted from a subject from group $\mathrm{C}>60$. Equal amounts of total protein were used for M, NR and LR samples. Immunoblotted proteins were the lipid raft hallmarkers caveolin-1 (cav-1) and flotillin-1, amyloid- $\beta$ protein precursor (A $\beta \mathrm{PP})$, also known as lipid raft resident, and non-raft membrane associated proteins $\mathrm{Na}^{+} / \mathrm{K}^{+}$ATPase $\alpha_{1}$ subunit (ATPase) and clathrin. (C) Summary of lipid analyses of lipid rafts and non-rafts fractions from group C $>60(n=10) .{ }^{* *}, *$ statistically different from non-raft with $p<0.01$ and $p<0.05$, respectively. SM: sphingomyelin, CHO: cholesterol, PC: phosphatidylcholine, PS: phosphatidylserine, PI: phosphatidylinositol, PG: phosphatidylglycerol, PE: phosphatidylethanolamine.

raft fractions. Within saturates, palmitic (16:0) and stearic (18:0) fatty acids accounted for more than $90 \%$ of saturates (see Table 3). In contrast, the contents of phosphatidylcholine (PC), phosphatidylserine (PS), phosphatidylinositol (PI), phosphatidylglycerol (PG), and phosphatidylethanolamine (PE) were significantly smaller in lipid rafts compared to non-raft fractions (Fig. 1C). Taken together, these experimental data demonstrate that the protein and lipid profiles of fraction 1 correspond to the expected features of highly purified lipid rafts.

Detailed analyses of fatty acids revealed that lipid rafts exhibited significant contents of monoene fatty acids (15-18\%) and n-3 long chain polyunsaturated fatty acids (n-3 LCPUFA) (5-7\%), specifically oleic acid (18:1n-9) and docosahexaenoic acid (DHA; 22:6n-3), while eicosapentaenoic acid (EPA, 20:5n-3) levels (the other essential n-3 LCPUFA) were negligible (Table 3 ). Arachidonic acid (20:4n-6) was also present in signifi- cant amounts in lipid rafts from all groups. These fatty acids are preferentially esterified on PE, PS, and PI. Accordingly, our analyses revealed significant levels of PE, PS, and PI, representing nearly $20 \%, 6.5 \%$, and $2.5 \%$, respectively, of the total phospholipids present in the lipid rafts of the three groups (Table 2). Thus, the lipid composition of human cortex lipid rafts closely resembles that previously reported in cell membranes from different sources $[1,4,27]$.

\section{Lipid rafts from control subjects}

Analyses performed in control samples $(\mathrm{C}<60$ and $\mathrm{C}>60$ groups) revealed no differences on either lipid classes or fatty acid composition of lipid rafts in the whole range of ages examined (24-85 years), suggesting a considerable stability in lipid raft lipid biochemistry throughout the lifespan. Specifically, no differences were observed in the levels of $\mathrm{CHO}, \mathrm{PE}$, and SM 
Table 2

Lipid class composition of brain cortex lipid raft samples from groups $\mathrm{C}<60$, $\mathrm{C}>60$ and $\mathrm{AD}$

\begin{tabular}{lrrr}
\hline \multicolumn{1}{c}{$\mathrm{C}<60$} & \multicolumn{1}{c}{$\mathrm{C}>60$} & \multicolumn{1}{c}{$\mathrm{AD}$} \\
\hline Sphingomyelin & $11.87 \pm 1.37$ & $11.43 \pm 1.44$ & $11.71 \pm 1.48$ \\
Phosphatidylcholine & $4.94 \pm 0.45$ & $5.35 \pm 0.49$ & $4.64 \pm 0.45$ \\
Phosphatidylserine & $6.53 \pm 0.29$ & $6.82 \pm 0.50$ & $6.59 \pm 0.47$ \\
Phosphatidylinositol & $2.13 \pm 0.11$ & $2.16 \pm 0.17$ & $3.05 \pm 0.62$ \\
Phosphatidylglycerol & $0.68 \pm 0.11$ & $0.70 \pm 0.10$ & $1.03 \pm 0.33$ \\
Phosphatidylethanolamine & $20.16 \pm 0.66$ & $20.97 \pm 0.57$ & $19.35 \pm 0.79$ \\
Sulphatides & $10.07 \pm 0.75$ & $10.56 \pm 0.68$ & $9.37 \pm 0.57$ \\
Cerebrosides & $4.82 \pm 0.87$ & $5.10 \pm 0.79$ & $4.43 \pm 0.75$ \\
Cholesterol & $35.41 \pm 1.54$ & $33.04 \pm 1.18$ & $36.40 \pm 1.51$ \\
Free Fatty Acids & $2.11 \pm 0.18$ & $2.17 \pm 0.28$ & $1.70 \pm 0.41$ \\
Sterol esters & $1.23 \pm 0.52$ & $1.68 \pm 0.60$ & $1.72 \pm 0.80$ \\
Neutral Lipids & $38.75 \pm 0.99$ & $36.90 \pm 1.41$ & $39.83 \pm 1.58$ \\
Polar Lipids & $61.22 \pm 0.98$ & $63.09 \pm 1.41$ & $60.17 \pm 1.58$ \\
Phospholipid/Cholesterol & $1.01 \pm 0.06$ & $1.11 \pm 0.07$ & $0.98 \pm 0.08$ \\
\hline \multicolumn{2}{c}{ Results are expressed as mole $\%$ and represent means \pm SEM } \\
\end{tabular}

Results are expressed as mole $\%$ and represent means \pm SEM.
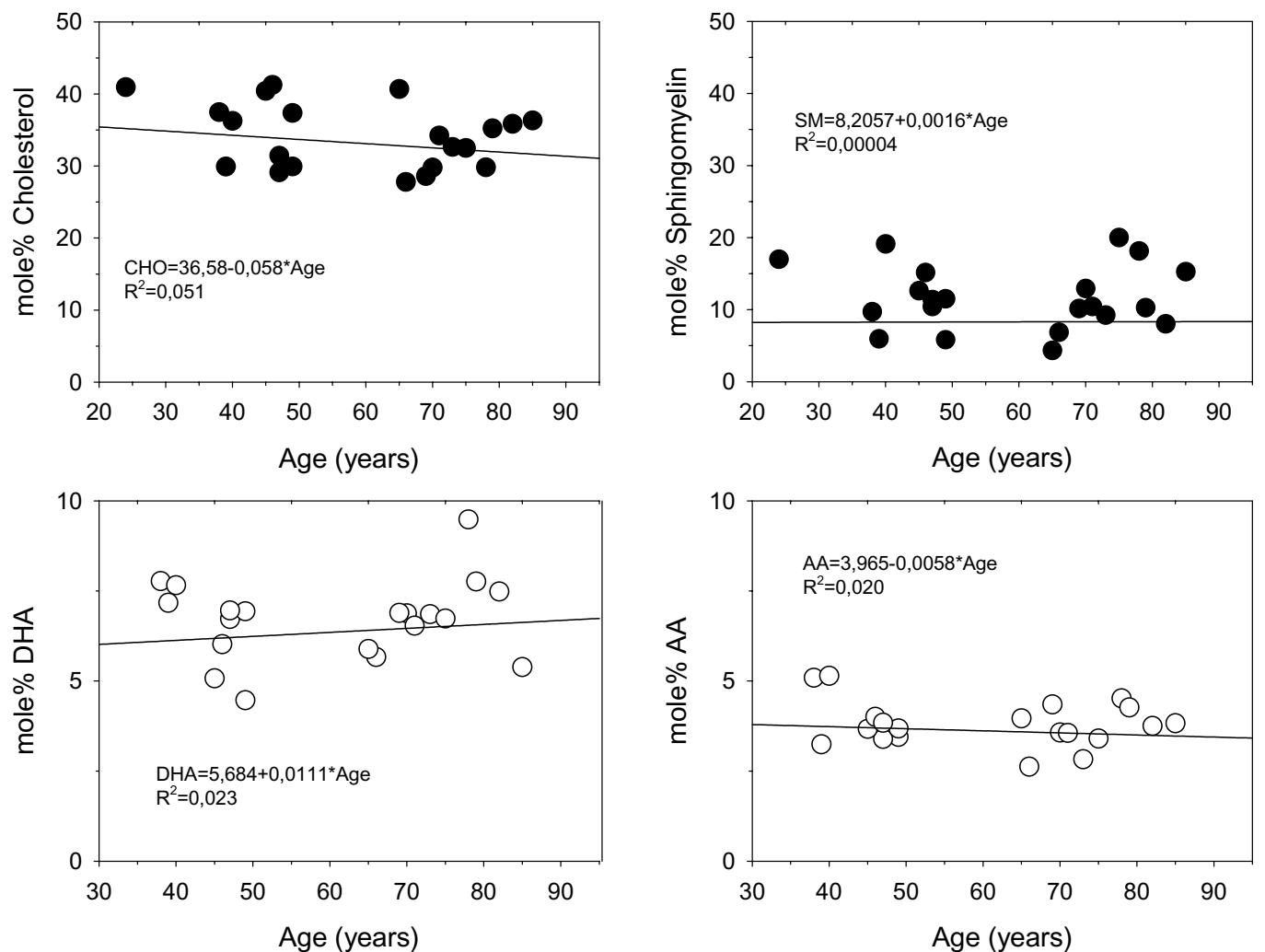

Fig. 2. Regression analyzes for Cholesterol (CHO), sphingomyelin (SM), docosahexaenoic acid (DHA), and araquidonic acid (AA) contents as a function of age in lipid rafts from control subjects. Linear regression equations and determination coefficients are indicated.

lipid classes, nor in the percentages of AA and DHA fatty acids of lipid raft from control samples as function of age (24-85 years) (Fig. 2). In addition, no gender differences were detected for any lipid class or fatty acid in any group (not shown).

Correlation analyses of all lipid variables showed that most bivariate relationships were similar between groups $\mathrm{C}>60$ and $\mathrm{C}<60$. Only slight differences were detected for some lipid classes such PE $(r=$ $-0.862, p<0.005)$, sultatides $(r=-0.863, p<$ $0.005)$, and cerebrosides $(r=-0.877, p<0.005)$, that were negatively correlated to $\mathrm{SM}$ in $\mathrm{C}<60$ but 
Table 3

Fatty acid composition of brain cortex lipid raft samples from groups $C<60, \mathrm{C}>60$ and ADs

\begin{tabular}{|c|c|c|c|c|c|c|}
\hline & $\mathrm{C}<60$ & & $C>60$ & & $\mathrm{AD}$ & \\
\hline $15: 0$ & $1.09 \pm 0.21$ & & $0.91 \pm 0.14$ & & $2.01 \pm 0.69$ & \\
\hline $16: 0$ & $24.84 \pm 1.13$ & & $24.10 \pm 1.31$ & & $23.62 \pm 1.17$ & \\
\hline $16: 1^{1}$ & $0.98 \pm 0.10$ & $\mathrm{~b}$ & $1.08 \pm 0.08$ & $\mathrm{~b}$ & $2.33 \pm 0.57$ & $\mathrm{a}$ \\
\hline $16: 4$ & $4.17 \pm 0.14$ & & $4.23 \pm 0.13$ & & $4.07 \pm 0.27$ & \\
\hline $18: 0$ & $21.81 \pm 0.39$ & & $22.05 \pm 0.43$ & & $21.01 \pm 0.89$ & \\
\hline $18: 1 \mathrm{n}-9$ & $17.66 \pm 0.51$ & $\mathrm{a}$ & $17.64 \pm 1.10$ & $\mathrm{a}$ & $15.15 \pm 0.53$ & $\mathrm{~b}$ \\
\hline $18: 1 \mathrm{n}-7$ & $4.48 \pm 0.28$ & & $4.99 \pm 0.32$ & & $6.26 \pm 0.94$ & \\
\hline $18: 2 n-6$ & $0.98 \pm 0.09$ & & $0.85 \pm 0.09$ & & $0.81 \pm 0.12$ & \\
\hline $20: 1^{2}$ & $1.15 \pm 0.18$ & & $1.08 \pm 0.19$ & & $0.98 \pm 0.19$ & \\
\hline $20: 4 n-6$ & $3.95 \pm 0.23$ & & $3.70 \pm 0.18$ & & $3.30 \pm 0.37$ & \\
\hline $22: 2 n-6$ & $0.56 \pm 0.07$ & $\mathrm{~b}$ & $0.68 \pm 0.09$ & $\mathrm{~b}$ & $1.24 \pm 0.21$ & $\mathrm{a}$ \\
\hline $22: 5 n-6$ & $0.75 \pm 0.09$ & $\mathrm{a}$ & $0.46 \pm 0.06$ & $\mathrm{~b}$ & $0.52 \pm 0.07$ & $a b$ \\
\hline $22: 6 n-3$ & $6.53 \pm 0.38$ & $\mathrm{a}$ & $6.87 \pm 0.34$ & $\mathrm{a}$ & $4.91 \pm 0.55$ & $\mathrm{~b}$ \\
\hline \multicolumn{7}{|l|}{ Totals } \\
\hline Saturates & $49.15 \pm 1.28$ & & $48.58 \pm 1.72$ & & $48.48 \pm 1.28$ & \\
\hline$n-9$ & $18.73 \pm 0.67$ & $\mathrm{a}$ & $18,87 \pm 1.15$ & $a b$ & $15.98 \pm 0.62$ & $\mathrm{~b}$ \\
\hline$n-3$ & $6.70 \pm 0.40$ & $a b$ & $7,11 \pm 0.37$ & $\mathrm{a}$ & $5.16 \pm 0.64$ & $\mathrm{~b}$ \\
\hline$n-6$ & $6.91 \pm 0.32$ & & $6,35 \pm 0.24$ & & $6.55 \pm 0.29$ & \\
\hline n-3 LCPUFA & $6.70 \pm 0.40$ & $a b$ & $7.11 \pm 0.37$ & $\mathrm{a}$ & $5.16 \pm 0.64$ & $\mathrm{~b}$ \\
\hline$n-3 / n-6$ & $0.98 \pm 0.07$ & $a b$ & $1.12 \pm 0.05$ & $\mathrm{a}$ & $0.77 \pm 0.08$ & $\mathrm{~b}$ \\
\hline 18:1/n-3 LCPUFA ${ }^{3}$ & $2.76 \pm 0.26$ & & $2.57 \pm 0.22$ & & $3.39 \pm 0.42$ & \\
\hline Saturates/n-3 & $7.52 \pm 0.43$ & $\mathrm{~b}$ & $6.98 \pm 0.38$ & $\mathrm{~b}$ & $11.18 \pm 1.19$ & $\mathrm{a}$ \\
\hline Saturates $/ \mathrm{n}-9$ & $2.66 \pm 0.15$ & & $2.72 \pm 0.25$ & & $3.07 \pm 0.18$ & \\
\hline Unsaturation index & $109.42 \pm 2.26$ & a & $110,34 \pm 2.41$ & $\mathrm{a}$ & $95.75 \pm 4,01$ & $\mathrm{~b}$ \\
\hline Peroxidability index & $85.73 \pm 3.60$ & $\mathrm{a}$ & $86.51 \pm 3.36$ & $\mathrm{a}$ & $66.81 \pm 5,90$ & $\mathrm{~b}$ \\
\hline
\end{tabular}

Results are expressed as mole $\%$ and represent means \pm SEM. Values in the same row bearing different superscript letters are significantly different $(p<0.05)$. Totals include some minor components not shown. ${ }^{1}$ Contains $n-9$ and $n-7$ isomers. ${ }^{2}$ Contains $n-11$ and $n-9$ isomers.

3 18:1n-9/n-3 LCPUFA.

not in $\mathrm{C}>60$ groups. Similarly, $\mathrm{CHO}$ was negatively correlated to PE in $\mathrm{C}<60$ group $(r=-0.693, p<$ 0.05 ) but not in $\mathrm{C}>60$ group.

Given the similarity in the lipid content of lipid rafts from control brains, data from both groups were pooled together and reanalyzed for multiple relationships between lipid classes and major fatty acids. The analyses revealed positive significant correlations for PC, PS, and PI versus DHA $(r=0.593, p<0.01 ; r=$ $0.714, p<0.001$ and $r=0.703, p<0.005$ for PC, PS and PI, respectively) (Figs 3A and 3B). Another important association was observed for PS and PI with AA $(r=0.670, p<0.005$ and $r=0.465, p<0.005$ for PS and PI, respectively) (Figs 3C and 3D). Interestingly, PE was not correlated to DHA or AA. Among saturates, stearic acid (18:0) was positively correlated to PS ( $r=0.565, p<0.01$, Fig. 3E) and negatively correlated to PE $(r=-0.516, p<0.05)$ but uncorrelated to PC or PI. With regards to palmitic acid (16:0), no significant correlations were detected for any of the phospholipids analyzed. Taken together these relationships might suggest that both 18:0 and DHA esterify PS in lipid rafts from control brains. Unlike whole cell membrane, PE seemed to be not associated with DHA in lipid rafts microdomains. It was also evident that a negative relationship between oleic acid (18:1n-9) and saturates $(r=-0.877, p<0.001)$ exists (Fig. 3F) indicating the negative relationship between both fatty acids in settling lipid raft fluidity.

\section{Lipid rafts from AD brains}

The proportion of phospholipids and cholesterol in the lipid rafts from frontal cortex of AD brains was similar and not significantly different from that of lipid rafts from healthy subjects (Table 2). Also, there were no significant changes of flotillin-1 content in lipid rafts from $\mathrm{AD}$ as compared to age-matched controls, a finding that may reflect that the presence and formation of rafts is unaffected in AD.

Nevertheless, despite the absence of changes in lipid classes composition from lipid rafts, there was a significant reduction of n-9, n-3, and n-3 LCPUFA in lipid rafts isolated from AD subjects (Table 3). ADinduced alterations of lipid raft n-3 and n-3 LCPUFA composition can be entirely attributed to the depletion of DHA levels, which represent more than $90 \%$ of the 

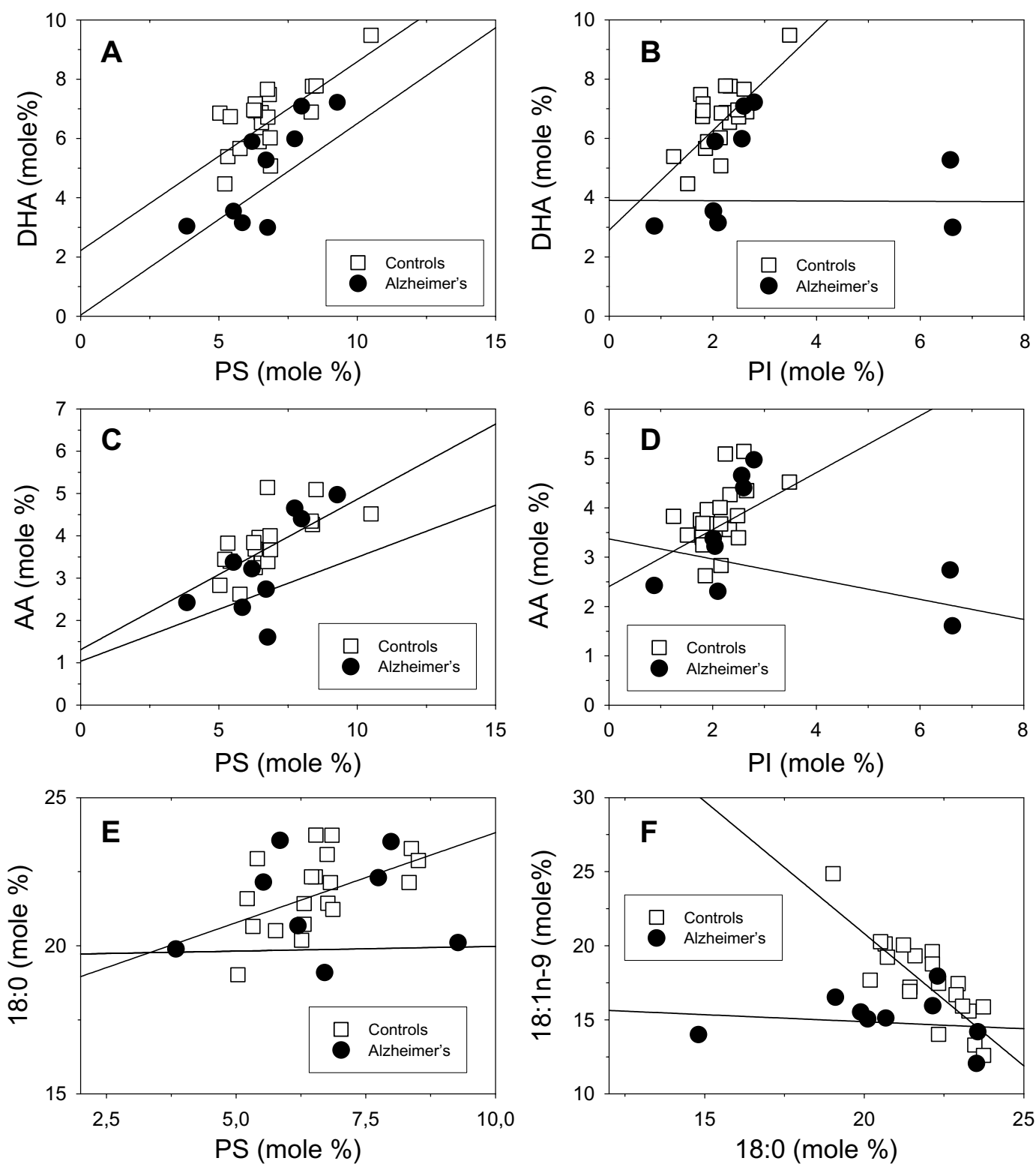

Fig. 3. Regression analyses for a subset of phospholipids and fatty acids in control ( $\square$ ) and AD (O) lipid rafts. A,B: linear relationships between PS (A) and PI (B) versus DHA; C,D: linear relationships between PS (C) and PI (D) versus AA; E: linear relationship between PS and palmitic acid (18:0); F: linear relationship between oleic acid (18:1n-9) and stearic acid (18:0). Correlation coefficients and statistical significances are indicated in the text. Units are expressed as mole percentage for all variables.

total $\mathrm{n}-3$ fatty acids in all groups. Thus, in the AD group the DHA content was $28 \%$ lower than in the agematched control group. Appreciable reductions of monoene 18:1n-9 and 20:4n-6 were also observed in lipid rafts from $\mathrm{AD}$ brains, yet for the later differences were not significant. Also, AD lipid rafts exhibited increased saturates $/ \mathrm{n}-3$ ratio and reduced unsaturation index (that could be entirely attributable to the reductions in $n-3$ LCPUFA and n-9 monounsaturated fatty acids) as well as a significant reduction in the peroxidability of membrane lipids. Interestingly, no significant differences were found between females and males for any lipid class or fatty acid in AD lipid rafts (not shown).

Analysis of correlation between all variables showed that some of the existent relationships between lipid classes and fatty acids were altered or disappeared in AD lipid rafts. Thus, the positive relationships between PI and DHA or AA (Figs 3B and 3D) and between PS 
and 18:0 (Fig. 3E) observed in control brains vanished in AD rafts. The same stands for the relationship between oleic acid (18:1n-9) and saturates, 16:0 or 18:0 (Fig. 3F). On the other hand, unlike control rafts, PE appeared to be positively correlated to AA and DHA $(r=0.871, p<0.005$ and $r=0.692, p<0.05$ for AA and DHA, respectively) while PI was negatively related to stearic acid $(r=-695, p<0.05)$ in $\mathrm{AD}$ microdomains (not shown).

A deeper insight into the lipid alteration of AD lipid rafts was obtained by using discriminant analysis. Our results showed that the first canonical function accounted for the great majority of the variation between groups $(91.8 \%)$ while the second canonical variable accounted only for $8.2 \%$. The variables which showed the highest absolute correlation with respect to every discriminate function were age, n3/n6 ratio, saturates/n 3 ratio, DHA, peroxidability index, 18:1n-9, PI and PE. The $1^{\text {st }}$ discriminant function (mainly determined by age variable) clearly separates $\mathrm{C}<60$ group from the rest of the groups, while the $2^{\text {nd }}$ function (defined by $\mathrm{n} 3 / \mathrm{n} 6$ ratio, saturates/n3 ratio, DHA, peroxidability index, 18:1n-9, $\mathrm{PI}$ and PE) separates $\mathrm{C}>60$ and AD groups (Fig. 4A). Sequential Chi-square test revealed that the $1^{\text {st }}$ discriminant function contributes to the discrimination of the groups to a large extent $\left(\chi^{2}=74.06, p<0.001\right)$, and according to the structure coefficients was mainly determined by age variable. In order to test whether the lipid composition per se could be used to identify groups, we performed additional analyses without the contribution of age. In this case, the contribution to overall variance of the first and second canonical functions was $77.5 \%\left(\chi^{2}=33.70, p<0.01\right)$ and $22.5 \%$ $\left(\chi^{2}=9.84, p>0.2\right)$, respectively. The $1^{\text {st }}$ discriminant function clearly separates AD group from control groups, while the $2^{\text {nd }}$ function roughly separates C $>60$ and $C<60$ groups (Fig. 4B). Structure coefficients revealed that the $n 3 / n 6$ ratio, saturates/n 3 ratio, DHA and n-9 fatty acids (mainly 18:1n-9) determine the $1^{\text {st }}$ discriminant function, while the $2^{\text {nd }}$ function was defined by the 22:5n- 6 content.

\section{DISCUSSION}

Our findings provide a new view of lipid rafts in human brain cortex as liquid-ordered $\left(l_{o}\right)$ membrane microdomains enriched in flotillin, cholesterol, sphingolipids, and saturated fatty acids but also containing small amounts of unsaturated fatty acids (specifically monounsaturated and n-3 LCPUFA),
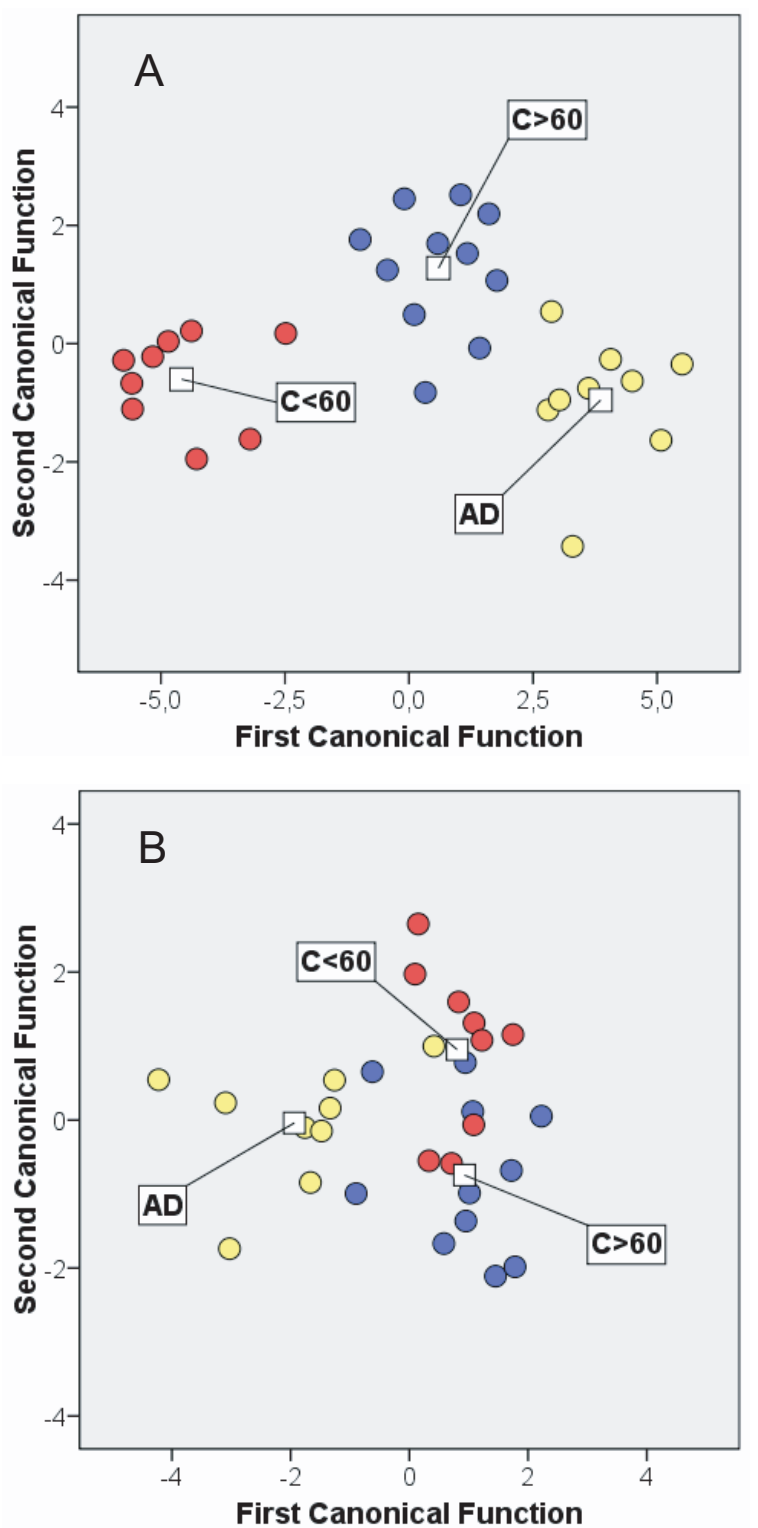

Fig. 4. Scatter plot of the first and second canonical variables in the discriminant function analyses for $\mathrm{C}>60, \mathrm{C}<60$ and $\mathrm{AD}$ groups. (A) including and (B) excluding age variable from analyses. Centroids for each group are represented as white filled squares. For details and interpretation see Results and Discussion sections.

phosphatidylserine, phosphatidylinositol, and phosphatidylethanolamine. Among n-3 LCPUFA contents in lipid rafts, our analyses showed that docosahexaenoic acid accounted for more than $95 \%$ of total n-3 LCPUFA, while eicosapentaenoic acid (EPA, 20:5n-3), the other important n-3 highly unsaturated fatty acid in brain lipids, were negligible. Also, signaling precursor arachidonic acid (20:4n-6) was also present in 
significant amounts in lipid rafts (around 3.5\%) from all groups and docosapentaenoic acid (DPA, 22:5n6 ), produced by further elongation and desaturation of arachidonic acid in neural cells, represent less than $0.8 \%$ of total fatty acids. These significant amounts of unsaturated fatty acids are reflected in the unsaturation index (average 109.88), which apparently contradicts the common view of lipid rafts as highly saturated microdomains [1]. However, increasing evidence indicate that lipid rafts are heterogeneous both in terms of their protein and lipid contents, and can be localized to different regions of the cell $[2,39]$. Indeed, several authors have found high levels of unsaturated fatty acids in lipid rafts isolated from different cell types, including nerve cell membranes [40,41]. Specifically, polyunsaturated lipids representing $3.4 \%$ of the total lipid were found in lipid rafts from rat brain [42], and much higher levels of polyunsaturated lipids (13.3\% of overall lipid) have been found in lipid rafts from RBL-2H3 cells [40]. The consequences of appreciable amounts of LCPUFA in lipid rafts are that these microdomains may exist in a more loosely packed disordered state that phase separate within the membrane due to their high cholesterol and sphingomyelin contents [1]. In this sense, it has been suggested that higher levels of polyunsaturated lipids lead to an imperfect ordering of rafts lipids that might allow accommodating transmembrane polypeptide helices that rafts would normally exclude [40].

Comparison of lipid rafts from control samples (C $<60$ and $\mathrm{C}>60$ groups) revealed no differences in the levels of CHO, PE, PS, and SM lipid classes, or in the percentages of saturates, monoenes, AA, and DHA fatty acids in the range of ages analyzed (24-85 years). This is interesting since changes in whole brain lipid composition as a function of age have been reported in normal subjects $[20,43]$. Thus, in the frontal cortex and hippocampus, PE and PC concentrations decrease by about $30 \%$ in the healthy elderly compared to young adults [20]. Also, DHA contents in the main brain phospholipids (PC and $\mathrm{PE}$ ) have been reported to be reduced in older compared to young subjects $[43,44]$. In agreement with our findings, studies performed on synaptosomal lipid rafts have shown that SM levels do not differ in mice from different groups of age [29]. Therefore, according to our present data, increasing age does not alter lipid raft composition in control subjects, suggesting the existence of homeostatic mechanisms whereby nerve cells tend to maintain the physicochemical structure of lipid rafts.

Correlation analyses of lipid classes and fatty acids in the lipid rafts of control subjects also revealed that
DHA was associated to PC, PS, and PI, rather than to PE. It was also evident the strong relationship between PS and 18:0, which is in good agreement with the notion that 18:0 and DHA esterify PS in lipid rafts at positions $s n-1$ and $s n-2$ of the phospholipid backbone, respectively [45]. In fact, such molecular association has been shown to represent the most abundant form of PS in neural membranes from human cortex [45], rat cortex [46], rat hippocampus [47], olfactory bulb [48], and photoreceptor discs [49]. In relation to the presence of this molecular species of PS containing DHA in lipid rafts, several studies have demonstrated its involvement in the modulation of PI3K/Akt and Raf-1 signaling pathways in neural cells $[50,51]$. The relationship between PS and DHA is complex and it appears that neuronal survival induced by DHA (and to a lesser extend docosapentaenoic acid 22:5n-6) depends on its capacity to increase PS in neural membranes [51]. Additionally, DHA is the precursor molecule of $(10,17 S)$ docosatriene (neuroprotectin D1 or NPD1), an oxygenated product of DHA which play an important role in supporting neuronal survival under pathological conditions, including $\mathrm{A} \beta-{ }_{42}$-induced neurotoxicity, by inducing neuroprotective and antiapoptotic gene expression [52].

Our analyses revealed no differences in the contents of flotillin-1, phospholipids, sphingomyelin, or cholesterol in lipid rafts from AD frontal cortex compared to healthy brains, an observation that reflects that the presence and formation of rafts is unaffected in AD. In agreement with our findings, a recent study by Molander-Melin and colleagues [3] reported no changes in the recovery or composition of the major membrane lipids, glycerophospholipid, $\mathrm{CHO}$, and SM in lipid rafts in the frontal cortex of AD brains. These observations are of critical importance since cholesterol has been shown to interact with $\mathrm{A} \beta$ in a reciprocal manner: $\mathrm{A} \beta$ impacts on cholesterol metabolism and modifications of cholesterol levels alter $\mathrm{A} \beta$ expression [53]. In fact, some have suggested that elevated cholesterol levels represent a risk factor for $\mathrm{AD}$, and a linkage of cholesterol and AD has been associated to the occurrence of ApoE4 [54,55]. However, it seems now clear that rather than the bulk brain cholesterol levels, changes in cholesterol nerve cell membrane domains, i.e., alterations in the transbilayer distribution of cholesterol, in particular in the exofacial leaflet of the membrane, could act to promote synthesis of $\mathrm{A} \beta$ and to catalyze the fibrillogenesis of soluble $\mathrm{A} \beta$ in $\mathrm{AD}$ [53]. On the other hand, a complex relationship has been proposed to exist between PSEN1 and membrane lipid 
micro-environment [56]. These authors have shown that brain membranes from mice expressing a human wild-type PSEN1 transgene are less fluid and contain higher cholesterol and sphingomyelin levels, suggesting that interaction of PSEN1 with lipids directly affects the fluidity of brain membranes [56].

Notwithstanding the absence of changes in lipid classes, our data showed for the first time that AD lipid rafts exhibited significant reductions in DHA (and consequently in n-3 fatty acids and n-3 LCPUFA, where docosahexaenoic acid represents about $90 \%$ of their total contents) when compared with age-matched controls. These findings are in consonance with the observations in different brain areas including frontal cortex and hippocampus from AD patients, where DHA in main DHA-containing phospholipids (PE and PS) are notably reduced [20-22,25,43]. The relevance of these observations is outstanding given the extremely low capacity of human brain to synthesize DHA through desaturation/elongation processes of its n-3 LCPUFA precursor $\alpha$-linolenic acid [57]. As a result, depletion of DHA in neural phospholipids cannot be mitigated by compensatory metabolic pathways even after large $\alpha$-linolenic acid dietary intakes [43,57].

Interestingly, DHA reduction in lipid rafts from AD brains was not accompanied by parallel increases of docosapentaenoic acid (DPA, 22:5n-6, Table 2) or negatively correlated to it (not shown), which is in contrast with what has been observed in rat brain microsomes in animals receiving $\mathrm{n}-3$ deficient diets [58], where the substitution of 18:0/22:6n-3 with 18:0/22:5n-6 likely provides an alternative mechanism for maintaining membrane fluidity and interactions with other membrane components, given the structural similarities of the two molecular species [45].

We have also observed that, in absolute terms, AA was slightly reduced in AD lipid rafts, but more interestingly, that the positive significant correlation between PI and 20:4n-6 demonstrated in age-matched controls, completely disappeared in AD lipid rafts. Given that PI is considered to be the main AA-containing phospholipid in neural membranes and that phosphoinositide metabolites have been linked to synaptic survival, plasticity, and long-term potentiation [59,60], alterations of PI molecular composition at the raft microdomains likely commit nerve cells to abnormal intracellular signaling underlying synaptic dynamics in AD. In agreement, reduced levels of PI-derived oleic and arachidonic acids have been reported to be significantly decreased in whole cell membrane in the hippocampus of AD subjects [22].
Significant reductions of monoene $18: 1 n-9$ were also detected in lipid rafts from AD brains. One additional important observation derived from correlation analyses performed here is that the significant negative relationship between 18:0 and 18:1n-9 observed in lipid rafts from healthy brains vanished in AD samples (Fig. 3). Such relationship is physico-chemically relevant since the ratio between both fatty acids represents an evolutionary conserved mechanism to preserve the homeoviscous state of cell membranes in response to different forms of physical and/or chemical stress [61, $62]$. It can be hypothesized that the reduction in $18: 1 n-$ 9 together with disappearance of the relationship between 18:0 and 18:1n-9 in AD lipid rafts might indicate a down-regulation of $\Delta 9$-desaturase, the enzyme responsible for the synthesis of n-9 monounsaturated fatty acids from their saturated precursors [63], which would result in a concomitant loss of the ability to adjust lipid raft physical order. This interesting hypothesis is being currently assessed in brain samples from humans and $\mathrm{A} \beta \mathrm{PP} / \mathrm{PS} 1$ transgenic mice in our laboratory.

AD lipid rafts also displayed increased saturates $/ n-3$ ratio and reduced unsaturation index, which indicates that raft microdomains from AD brain cortex are notably more viscous and liquid-ordered than in the agematched control group. Alternatively, the reduction of DHA and 18:1n-9 contents in raft domain phospholipids in the $\mathrm{AD}$ group would alter the structure of lipid rafts compared to normal subjects. Indeed, it has been experimentally demonstrated that n-3 LCPUFA, mainly DHA, are incorporated into both cholesterol and sphingolipid-rich detergent-resistant liquidordered $\left(l_{\mathrm{o}}\right)$ and liquid disordered $\left(l_{\mathrm{d}}\right)$ plasma membrane microdomains in many cell types [26-28,64], but the poor affinity of DHA and perhaps other long chain PUFA for cholesterol provides a lipid-driven mechanism for lateral phase separation of cholesteroland sphingolipid-rich lipid microdomains from the surrounding $l_{\mathrm{d}}$ phase in model membranes $[65,66]$ altering the size, stability, and distribution of cell surface lipid microdomains such as rafts. Furthermore, it has been proposed that microdomain PUFA impoverishment may have profound consequences in the dynamic partitioning of acylated proteins, membrane order and fluidity, phase behavior, elastic compressibility, ion permeability, fusion, rapid flip-flop, receptor binding and resident protein function, thereby altering signal transduction events $[31,65,67]$.

Another consequence of the reduction in the unsaturation index of AD lipid rafts is the reduction in the peroxidability of membrane lipids. It has been demon- 
strated that polyunsaturated fatty acids are very susceptible to the oxidation induced by free radicals, generating specific reactive aldehydes, such as malondialdehyde or 4-hydroxynonenal $[37,68]$. The important PUFA content in brain tissue and its high oxygen consumption support the possible significance of lipid peroxidation-derived processes in brain aging and AD pathogenesis $[69,70]$. The significant reduction of LCPUFA and peroxidability and unsaturation indexes observed in lipid rafts from AD brains is consistent with a progressive generation of aldehyde reactive species and other lipoperoxides during the development of $\mathrm{AD}$ pathology. Such generation of LCPUFA-related reactive species is likely to be buffered in control aged brains, as revealed by comparison with $\mathrm{C}<60$ control brains (Table 3 ), which agrees with the notion that mechanisms involved in cellular antioxidant defense must have been depressed in late phases of AD [71].

Finally, considering that the differences between normal and AD lipid rafts involved not only individual lipid parameters but also a number of linear relationships between them, we performed discriminant function analyses to check whether lipid rafts from different groups could be defined from a multivariate approach. Our analyses were conclusive and revealed that, independently of a priori conditioning factors (age and Braak stage), control and AD groups could be resolved by means of two canonical functions (see Fig. 4B). The first of these discriminant functions (defined by predictive variables $\mathrm{n} 3 / \mathrm{n} 6$ ratio, saturates/n3 ratio, DHA and 18:1n-9) clearly separated AD from control groups, while the second function (defined by $22: 5 n-6$ ) seemingly separated groups $C>60$ and $C<60$. We can conclude from these analyses that lipid biochemical composition of lipid raft per se can be used as predictive tool to determine the presence of AD pathology and, to a lesser extent, to establish the influence of aging.

In summary, our present results provide the first detailed view of the fatty acid composition of lipid rafts isolated from frontal cerebral cortex of human brains. The observations demonstrate the presence of significant amounts of monounsaturated (especially 18:1n-9) and polyunsaturated fatty acids (DHA and AA), in the biochemical composition of lipid raft and point to the existence of homeostatic mechanisms preserving lipid raft status in normal frontal cortex. The disruption of such mechanisms in AD brains alters lipid raft composition and physico-chemical properties, which may explain the abnormal lipid raft signaling processes observed in AD.

\section{ACKNOWLEDGMENTS}

This work was funded by grants SAF2007-66148C02-02 (Spanish Ministry of Education and Science), PI08/0582 (Spanish Ministry of Health, Instituto de Salud Carlos III), and supported by the European Commission under the Sixth Framework Programme (BrainNet Europe II, LSHM-CT-2004-503039). We thank PULEVA BIOTECH (Spain) for collaborating in the development of lipid strategies in the present project. We are indebted to Dr. Miguel Molina for his generous aid and helpful comments on the interpretation of multivariate analyses. This work is dedicated to the memory of Ignacio J. Lozano Soldevilla, a beloved colleague who always brought jollity to the art of producing science, even at the twilight of his life.

Authors' disclosures available online (http://www.jalz.com/disclosures/view.php?id=121).

\section{REFERENCES}

[1] Brown DA, London E (2000) Structure and function of sphingolipid- and cholesterol-rich membrane rafts. $J$ Biol Chem 275, 17221-17224.

[2] Pike LJ (2003) Lipid rafts: bringing order to chaos. J Lipid Res 44, 655-667.

[3] Molander-Melin M, Blennow K, Bogdanovic N, Dellheden B, Mansson JE, Fredman P (2005) Structural membrane alterations in Alzheimer brains found to be associated with regional disease development; increased density of gangliosides GM1 and GM2 and loss of cholesterol in detergent-resistant membrane domains. J Neurochem 92, 171-182.

[4] Michel V, Bakovic M (2007) Lipid rafts in health and disease. Biol Cell 99, 129-140.

[5] Duyckaerts C, Dickson DW (2003) Neurodegeneration: The molecular pathology of dementia and movement disorders. ISN Neuropath. Press, Basel.

[6] Lee SJ, Liyanage U, Bickel PE, Xia W, Lansbury PT Jr, Kosik KS (1998) A detergent-insoluble membrane compartment contains A beta in vivo. Nat Med 4, 730-734.

[7] Hayashi H, Mizuno T, Michikawa M, Haass C, Yanagisawa K (2000) Amyloid precursor protein in unique cholesterol-rich microdomains different from caveolae-like domains. Biochim Biophys Acta 1483, 81-90.

[8] Ehehalt R, Keller P, Haass C, Thiele C, Simons K (2003) Amyloidogenic processing of the Alzheimer beta-amyloid precursor protein depends on lipid rafts. J Cell Biol 160, 113-123.

[9] Tikkanen R, Icking A, Beicht P, Waneck GL, Volker H (2002) The receptor-bound N-terminal ectodomain of the amyloid precursor protein is associated with membrane rafts. Biol Chem 383, 1855-1864.

[10] Vetrivel KS, Cheng H, Kim SH, Chen Y, Barnes NY, Parent AT, Sisodia S, Thinakaran G (2005) Spatial segregation of gammasecretase and substrates in distinct membrane domains. J Biol Chem 280, 25892-25900.

[11] Ikezu T, Trapp BD, Song KS, Schlegel A, Lisanti MP, Okamoto $\mathrm{T}$ (1998) Caveolae, plasma membrane microdomains for alpha-secretase-mediated processing of the amyloid precursor protein. J Biol Chem 273, 10485-10495. 
[12] Marlow L, Cain M, Pappolla MA, Sambamurti K (2003) Betasecretase processing of the Alzheimer's amyloid protein precursor (APP). J Mol Neurosci 20, 233-239.

[13] Riddell DR, Christie G, Hussain I, Dingwall C (2001) Compartmentalization of beta-secretase (Asp2) into low-buoyant density, noncaveolar lipid rafts. Curr Biol 11, 1288-1293.

[14] Cordy JM, Hussain I, Dingwall C, Hooper NM, Turner AJ (2003) Exclusively targeting beta-secretase to lipid rafts by GPI-anchor addition up-regulates beta-site processing of the amyloid precursor protein. Proc Natl Acad Sci USA 100, 11735-11740.

[15] Vetrivel KS, Cheng H, Lin W, Sakurai T, Li T, Nukina N, Wong PC, Xu H, Thinakaran G (2004) Association of gammasecretase with lipid rafts in post-Golgi and endosome membranes. J Biol Chem 279, 44945-44954.

[16] Hattori C, Asai M, Onishi H, Sasagawa N, Hashimoto Y, Saido TC, Maruyama K, Mizutani S, Ishiura S (2006) BACE1 interacts with lipid raft proteins. J Neurosci Res 84, 912-917.

[17] Hur JY, Welander H, Behbahani H, Aoki M, Franberg J, Winblad B, Frykman S, Tjernberg LO (2008) Active $\gamma$-secretase is localized to detergent-resistant membranes in human brain. FEBS J 275, 1174-1187.

[18] Uauy R, Hoffman DR, Peirano P, Birch DG, Birch EE (2001) Essential fatty acids in visual and brain development. Lipids 36, 885-895

[19] Lane RM, Farlow MR (2005) Lipid homeostasis and apolipoprotein $\mathrm{E}$ in the development and progression of Alzheimer's disease. J Lipid Res 46, 949-968.

[20] Soderberg M, Edlund C, Kristensson K, Dallner G (1991) Fatty acid composition of brain phospholipids in aging and in Alzheimer's disease. Lipids 26, 421-425.

[21] Soderberg M, Edlund C, Alafuzoff I, Kristensson K, Dallner $\mathrm{G}$ (1992) Lipid composition in different regions of the brain in Alzheimer's disease/senile dementia of Alzheimer's type. $J$ Neurochem 59, 1646-1653.

[22] Prasad MR, Lovell MA, Yatin M, Dhillon H, Markesbery WR (1998) Regional membrane phospholipid alterations in Alzheimer's disease. Neurochem Res 23, 81-88.

[23] Hashimoto M, Hossain S, Shimada T, Sugioka K, Yamasaki H, Fujii Y, Ishibashi Y, Oka JI, Shido O (2002) Docosahexaenoic acid provides protection from impairment of learning ability in Alzheimer's disease model rats. J Neurochem 81, 1084-1091.

[24] Calon F, Lim GP, Yang F, Morihara T, Teter B, Ubeda O, Rostaing P, Triller A, Salem N. (2004) Docosahexaenoic acid protects from dendritic pathology in an Alzheimer's disease mouse model. Neuron 43, 633-645.

[25] Young G, Conquer J (2005) Omega-3 fatty acids and neuropsychiatric disorders. Reprod Nutr Dev 45, 1-28.

[26] Fan YY, McMurray DN, Ly LH, Chapkin RS (2003) Dietary (n-3) polyunsaturated fatty acids remodel mouse T-cell lipid rafts. J Nutr 133, 1913-2190.

[27] Ma DW, Seo J, Davidson LA, Callaway ES, Fan YY, Lupton JR, Chapkin RS (2004a) n-3 PUFA alter caveolae lipid composition and resident protein localization in mouse colon. FASEB J 18, 1040-1042.

[28] Ma DW, Seo J, Switzer KC, Fan YY, McMurray DN, Lupton JR, Chapkin RS (2004b) n-3 PUFA and membrane microdomains: a new frontier in bioactive lipid research. $J$ Nutr Biochem 15, 700-706.

[29] Igbavboa U, Eckert GP, Malo TM, Studniski AE, Johnson LNA, Yamamoto N, Kobayashi M, Fujita SC, Appel TR, Müller WE, Wood WG, Yanagisawa K (2005) Murine synaptosomal lipid raft protein and lipid composition are altered by expression of human apoE 3 and 4 and by increasing age. $J$ Neurol Sci 229-230, 225-232.

[30] Chen W, Jump DB, Esselman WJ, Busik JV (2007) Inhibition of cytokine signaling in human retinal endothelial cells through modification of caveolae/lipid rafts by docosahexaenoic acid. Invest Ophthalmol Vis Sci 48, 18-26.

[31] Chapkin RS, Wang N, Fan YY, Lupton JR, Prior IA (2008)Docosahexaenoic acid alters the size and distribution of cell surface microdomains. Biochim Biophys Acta 1778, 466-471.

[32] Braak H, Braak E, Peter J, Morrison JH (1999) Neurodegenerative and age-related changes in structure and function of cerebral cortex, in Cerebral cortex, (Peters A., Morrison J. H., eds), Vol. 14. Kluwer Academic/Plenum Publishers, Dordrecht.

[33] Braak H, Alafuzoff I, Arzberger T, Kretzschmar H, Del Tredici K (2006) Staging of Alzheimer disease-associated neurofibrillary pathology using paraffin sections and immunocytochemistry. Acta Neuropathol 112, 389-404.

[34] Mukherjee A, Arnaud L, Cooper JA (2003) Lipid-dependent recruitment of neuronal Src to lipid rafts in the brain. $J$ Biol Chem 278, 40806-40814.

[35] Christie WW (1982) Lipids Analysis. Pergamon Press, Oxford.

[36] Olsen RE, Henderson RJ (1989) The rapid analysis of neutral and polar marine lipids using double development HPTLC and scanning densitometry. J Exp Mar Biol Ecol 129, 189-197.

[37] Cosgrove JP, Church DF, Pryor WA (1987) The kinetics of the autoxidation of polyunsaturated fatty acids. Lipids 22, 299304.

[38] Huberty CJ (1994) Applied discriminant analysis. WileyInterscience. New York.

[39] Pike LJ (2004) Lipid rafts: heterogeneity on the high seas. Biochem J 378, 281-292.

[40] Fridriksson EK, Shipkova PA, Sheets ED, Holowka D, Baird B, McLafferty FW (1999) Quantitative analysis of phospholipids in functionally important membrane domains from RBL-2H3 mast cells using tandem high-resolution mass spectrometry. Biochemistry 38, 8056-8063.

[41] Pike LJ, Han X, Chung KN, Gross R (2002) Lipid rafts are enriched in arachidonic acid and plasmenylethanolamine and their composition is independent of caveolin-1 expression: a quantitative electrospray ionization/mass spectrometric analysis. Biochemistry 41, 2075-2088.

[42] Brugger B, Graham C, Leibrecht I, Mombelli E, Jen A, Wieland F, Morris R (2004) The membrane domains occupied by glycosylphosphatidylinositol-anchored prion protein and Thy-1 differ in lipid composition. J Biol Chem 279, 75307536.

[43] Plourde M, Fortier M, Vandal M, Tremblay-Mercier J, Freemantle E, Bégin M, Pifferi F, Cunnane SC (2007) Unresolved issues in the link between docosahexaenoic acid and Alzheimer's disease. Prostaglandins Leukot Essent Fatty Acids 77, 301-308.

[44] Horrocks LA, Farooqui AA (2004) Docosahexaenoic acid in the diet: its importance in maintenance and restoration of neural membrane function. Prostaglandins Leukot Essent Fatty Acids 70, 361-372.

[45] Mozzi R, Buratta S, Goracci G (2003) Metabolism and functions of phosphatidylserine in mammalian brain. Neurochem Res 28, 195-214.

[46] Little SJ, Lynch MA, Manku M, Nicolaou A (2007) Docosahexaenoic acid-induced changes in phospholipids in cortex of young and aged rats: a lipidomic analysis. Prostaglandins Leukot Essent Fatty Acids 77, 155-162. 
[47] Murthy M, Hamilton J, Greiner RS, Moriguchi T, Salem NJr, Kim HY (2002) Differential effects of n-3 fatty acid deficiency on phospholipid molecular species composition in the rat hippocampus. J Lipid Res 43, 611-617.

[48] Hamilton L, Greiner R, Salem NJr., Kim HY (2000) n-3 fatty acid deficiency decreases phosphatidylserine accumulation selectively in neuronal tissues. Lipids 35, 863-869.

[49] Aveldano MI, Bazan NG (1983) Molecular species of phosphatidylcholine, -ethanolamine, -serine, and -inositol in microsomal and photoreceptor membranes of bovine retina. $J$ Lipid Res 24, 620-627.

[50] Kim HY, Akbar M, Lau A (2003) Effects of docosapentaenoic acid on neuronal apoptosis. Lipids 38, 453-457.

[51] Akbar M, Calderon F, Wen Z, Kim HY (2005) Docosahexaenoic acid: A positive modulator of Akt signaling in neuronal survival. Proc Natl Acad Sci U S A 102, 10858-10863.

[52] Lukiw WJ, Cui JG, Marcheselli VL, Bodker M, Botkjaer A, Gotlinger K, Serhan C N, Bazan N (2005) A role for docosahexaenoic acid-derived neuroprotectin D1 in neural cell survival and Alzheimer disease. J Clin Invest 115, 2774-2783.

[53] Gibson W, Eckert GP, Igbavboa U, Müller WE (2003) Amyloid beta-protein interactions with membranes and cholesterol: causes or casualties of Alzheimer's disease. Biochim Biophys Acta 1610, 281-290.

[54] Cedazo-Mínguez A (2007) Apolipoprotein E and Alzheimer's disease: molecular mechanisms and therapeutic opportunities. Cell Mol Med 11, 1227-1238.

[55] Donahue JE, Johanson CE (2008) Apolipoprotein E, amyloidbeta, and blood-brain barrier permeability in Alzheimer disease. J Neuropathol Exp Neurol 67, 261-270.

[56] Eckert GP, Müller WE (2009) Presenilin 1 modifies lipid raft composition of neuronal membranes. Biochem Biophys Res Commun 382, 673-677.

[57] Plourde M, Cunnane SC (2007) Extremely limited synthesis of long chain polyunsaturates in adults: implications for their dietary essentiality and use as supplements. Appl Physiol Nutr Metab 32, 619-634.

[58] García MC, Ward G, Ma YC, Salem N, Kim HY (1998) Effect of docosahexaenoic acid on the synthesis of phosphatidylserine in rat brain microsomes and C6 glioma cells. J Neurochem 70, 24-30.

[59] Kelly A, Lynch MA (2000) Long-term potentiation in dentate gyrus of the rat is inhibited by the phosphoinositide 3-kinase inhibitor, wortmannin. Neuropharmacology 39, 643-651.

[60] Osborne SL, Meunier FA, Schiavo G (2001) Phosphoinositides as key regulators of synaptic function. Neuron 32, 9-12.

[61] McDonald AG (1988) Application of the theory of homeoviscous adaptation to excitable membranes: pre-synaptic processes. Biochem J 256, 313-327.

[62] Pamplona R, Barja G, Portero-Otín M (2002) Membrane fatty acid unsaturation, protection against oxidative stress, and maximum life span: a homeoviscous-longevity adaptation? Ann N Y Acad Sci 959, 475-490.

[63] Nakamura MT, Nara TY (2004) Structure, function, and dietary regulation of delta6, delta5, and delta9 desaturases. Annu Rev Nutr 24, 345-376.

[64] Fan YY, Ly L, Barhoumi R, McMurray DN, Chapkin RS (2004) Dietary docosahexaenoic acid suppresses T cell protein kinase $\mathrm{C}$ theta lipid raft recruitment and IL-2 production. $J$ Immunol 173, 6151-6160.

[65] Stillwell W, Wassall SR (2003) Docosahexaenoic acid: membrane properties of a unique fatty acid. Chem Phys Lipids $\mathbf{1 2 6}$, $1-27$.

[66] Shaikh S. R., Dumaual A. C., Castillo A., LoCascio D., Siddiqui R. A., Stillwell W. and Wassall S. R. (2004) Oleic and docosahexaenoic acid differentially phase separate from lipid raft molecules: a comparative NMR, DSC, AFM, and detergent extraction study. Biophys $J$ 87, 1752-1766.

[67] Shaikh SR, Caffrey M, Stillwell W, Cherezov V, Wassall SR (2003) Interaction of cholesterol with a docosahexaenoic acid-containing phosphatidylethanolamine: trigger for microdomain/raft formation? Biochemistry 42, 12028-12037.

[68] Esterbauer H, Schaur RJ, Zollner H (1991) Chemistry and biochemistry of 4-hydroxynonenal, malonaldehyde and related aldehydes. Free Radic Biol Med 11, 81-128.

[69] Aksenov MY, Aksenova MV, Butterfield DA, Geddes JW, Markesbery WR (2001) Protein oxidation in the brain in Alzheimer's disease. Neuroscience 103, 373-383.

[70] Pamplona R, Dalfó E, Ayala V, Bellmunt J, Prat J, Ferrer I, Portero MJ (2005) Proteins in human brain cortex are modified by oxidation, glycoxidation, and lipoxidation: effects of Alzheimer's disease and identification of lipoxidation targets. $J$ Biol Chem 280, 21522-21530.

[71] Shi Q, Gibson GE (2007) Oxidative stress and transcriptional regulation in Alzheimer disease. Alzheimer Dis Assoc Disord 21, 276-291. 